\title{
STUDI DESKRIPTIF HYGIENE SANITASI PENGOLAHAN MAKANAN DI INSTALASI GIZI RSJD dr. ARIF ZAINUDIN SURAKARTA TAHUN 2016
}

\author{
Afdela Fiftina Merdekawati ${ }^{1)}$, Teguh Widiyanto ${ }^{2)}$ \\ Jurusan Kesehatan Lingkungan, Politeknik Kesehatan Kemenkes Semarang, \\ Jl.Raya Baturaden KM 12 Purwokerto, Indonesia
}

\begin{abstract}
Abstrak
STUDI DESKRIPTIF HYGIENE SANITASI PENGOLAHAN MAKANAN DI INSTALASI GIZI RSJD dr. Arif Zainudin SURAKARTA TAHUN 2016 Makanan yang sehat dan aman merupakan salah satu faktor yang penting untuk meningkatkan derajat kesehatan masyarakat. Berbagai macam penyakit dapat ditularkan pada pasien di rumah sakit melalui makanan akibat dari pengolahan makanan yang tidak sehat, oleh karena itu pengolahan makanan di rumah sakit perlu mendapat perhatian yang lebih seksama.. Penelitian ini bertujuan untuk mengetahui kondisi hygiene sanitasi pengolahan makanan di Instalasi Gizi. Jenis penelitian ini adalah observasional deskriptif, karena peneliti mengamati secara langsung terhadap kondisi nyata pada Instalasi Gizi. Subyek dari penelitian ini adalah penjamah makanan,tempat,upaya hygiene sanitasi pengolahan makanan, dan kualitas mikrobiologi minuman. Sampel dari penelitian ini adalah semua penjamah makanan yang berjumlah 10 orang, tiga sampel minuman teh siap saji. Pengambilan data dilakukan menggunakan instrumen Kuisoner, checklist dan pemeriksaan laboratorium. Hasil penelitian menunjukkan kondisi upaya hygiene sanitasi, personal hygiene penjamah, kondisi fisik instalasi gizi sudah memenuhi syarat. Hasil laboratorium pemeriksaan E.Coli menunjukkan 0/100ml sampel minuman teh. Kesimpulan penelitian ini adalah hygiene sanitasi pengolahan makanan di Instalasi Gizi RSJD dr. Arif Zainudin Surakarta sudah memenuhi syarat, personal hygiene penjamah makanan sudah memenuhi syarat, kondisi fisik instalasi gizi sudah memenuhi syarat, dan hasil Hasil pemeriksaan laboratorium pemeriksaan E.Coli menunjukkan 0/100ml sampel minuman teh, hal tersebut sudah sesuai dengan Kepmenkes No. 1204 tahun 2004 tentang kesehatan lingkungan rumah sakit, bahwa kadar E.Coli dalam makanan dan minuman yaitu harus 0/gr sampel makanan dan 0/100ml sampel minuman. Saran untuk Instalasi Gizi agar penjamah makanan selalu membiasakan menggunakan masker saat bekerja. Kata kunci hygiene sanitasi, instalasi gizi, kualitas mikrobiologi makanan dan minuman.
\end{abstract}

Kata kunci : hygiene sanitasi, instalasi gizi, kualitas mikrobiologi makanan dan minuman

\begin{abstract}
Study Desctiptive Hhygiene Sanitation Food Processing in Instalation Nutrition RSJD dr. Arif Zainudin Surakarta Tahun 2016 The health food and safe is one important factor to increas level public health. Various diseases can be transmitted to patients in hospiltals via food as a result of unhealthy food processing. This study has purpuse to know the foof condition of sanitary hygiene nin processing Installation RSJD dr. Arif Zainudin Surakarta. This type of research is observational descriptive, because research is observes directly the real situation in Installation Nutrition RSJD dr. Arif Zainudin Surakarta. The subjects of this study is a food handler, place, effort hygiene sanitari food processing, beverages microbiological quality. Samples of research is all food handlers of 10 people, one sample is instant tea. Data were collected using a questionaire instrument, checklist and laboratory test using interviewa and observation. The results show the state of their hygiene sanitation, personal hygiene handlers, physical condition nutrition installation got both criteria. The results of laboratory examination showed E.Coli inspection 0/100 $\mathrm{ml}$ samples of the tea. The conclusion of this study is food processing sanitation hygiene in Installation RSJD dr. Arif Zainudin Surakarta are good, personal hygiene of food handlers has been good, physicial condition nutrition installation has been good and the results of laboratory show E.Coli 0/100 ml samples of the tea, it is in conformity with Kemenkes No. 1204 of 204 on the environmental health of the hospital, that E.Coly levels in food and beverages that should be $0 / \mathrm{g}$ sample the food and 0/100 $\mathrm{ml}$ beverage samples. Advicee for intallation nutrition so that the food handlers always used to use a mask when work. Keywords hygiene sanitation, nutrition installation, microbiological quality of food and beverages.
\end{abstract}

Keywords : hygiene sanitation, nutrition instalation, Microbiological quality of food

\section{PENDAHULUAN}

Makanan merupakan kebutuhan dasar manusia untuk melanjutkan kehidupan. Makanan yang

1) Email : afdelafiftina1995@yahoo.com

2) Email : teguhwidiyanto007@gmail.com dibutuhkan harus sehat dalam arti memiliki nilai gizi yang optimal seperti : vitamin, mineral hidrat arang, lemak, dan lainnya. Makanan harus murni dan utuh 
dalam arti tidak mengandung bahan pencemar serta harus hygiene. Bila salah satu faktor tersebut terganggu makanan yang dihasilkan akan menimbulkan gangguan kesehatan dan penyakit bahkan keracunan makanan.

Konsep personal hygiene dalam kehidupan seharihari merupakan hal yang sangat penting dan harus diperhatikan karena konsep personal hygiene akan mempengaruhi kesehatan seseorang. Kebersihan itu sendiri sangat dipengaruhi oleh nilai individu dan kebiasaan. Hal-hal yang sangat berpengaruh itu diantaranya kebudayaan, sosial, keluarga, pendidikan presepsi seseorang terhadap kesehatan.

Masalah kesehatan adalah suatu masalah yang sangat kompleks yang saling berkaitan dengan masalah lain diluar kesehatan itu sendiri. Pemecahan masalah kesehatan masyarakat, tidak hanya dilihat dari segi kesehatannya sendiri, tetapi harus dilihat dari seluruh segi yang ada pengaruhnya terhadap masalah sehat atau sakit atau kesehatan tersebut. Banyak falktor yang mempengaruhi derajat kesehatan, baik kesehatan individual maupun kesehatan masyarakat. Salah satunya adalah hygiene dan sanitasi makanan.

Bila pengolahan makanan di rumah sakit tidak ditanganiu dengan saniter dan htygiene maka sudah tentu akan menimbulkan dampak buruk bagi pasien, pengunjung atau petugas rumah sakit itu sendiri.

Tujuan penelitian ini adalah untuk mengetahui penerapan hygiene sanitasi pengolahan makanan dengan menggunakan metode pengolahan enam prinsip hygiene sanitasi makanan di RSJD dr. Arif Zainudin Surakarta Tahun 2016.

\section{METODE}

Penelitian ini menggunakan metode observasional deskriptif, karena peneliti mengamati secara langsungg terhadap kondisi yang ada pada Instalasi Gizi RSJD dr. Arif Zainudin Surakarta, dengan menggunakan instrumen berupa checklist.

\section{III.HASIL}

Hasil observasi terhadap enam prinsip hygiene sanitasi pengolahan makanan

a. Kondisi pengamanan bahan makanan

Hasil observasi terhadap bahan-bahan makanan yang datang dari suplayer, secara umum makanan dalam kondisi baik. Selanjutnya makanan digolongkan sesuai jenisnya, basah atau kering dan di cuci untuk disimpan atau diolah.

Berdasarkan hasil pengamatan menggunakan instrumen berupa checklist menunjukkan bahwa pengamanan bahan makanan di Instalasi Gizi RSJD dr. Arif Zainudin Surakarta sudah memenuhi syarat yaitu dengan presentase 100\%.

b. Kondisi penyimpanan bahan makanan

Penyimpanan bahan makanan digolongkan dalam dua jenis, yaitu bahan makanan basah dan bahan makanan kering. Bahan makanan basah meliputi sayur-sayuran, buah-buahan, daging, tempe, tahu, dan bumbu-bumbu rempah-rempah disimpan dalam gudang penyimpanan bahan makanan basah atau masuk ke lemari es sebelum dibawa di ruang pengolahan.

Hasil observasi Hasil observasi menunjukkan bahwa penyimpanan bahan makanan sudah memenuhi syarat dengan hasil presentase $75 \%$, sedangkan penilaian yang tidak memenuhi syarat dengan presentase 25\%.

c. Cara pengolahan bahan makannan

Observasi yang dilakukan pada proses pengolahan makanan melliputi personal hygienen penjamah makanan dan perilaku penjamah makanan secara umum, alat pengolahan yang digunakan, tempat pengolahan dan cara pengolahan.

Hasil observasi menunjukkan bahwa cara pengolahan bahan makanan di Instalasi Gizi RSJD dr. Arif Zainudin Surakarta sudah memenuhi syarat dengan presentase $100 \%$.

Proses pengolahan bahan makanan menjadi makanan jadi selalu dilakukan sedekat mungkin dengan waktu penyajian makanan karena untuk mencegah terjadinya makanan yang akan di sajikan benjadi busuk atau rusak. Proses pengolahan makanan, semua peralatan yang digunakanan menggunakan alat yang anti karat, utuh dan tidak mengandung bahan beracun, serta semua penjamah makanan menggunakan alat pelindung diri lengkap untuk menghindari kecelakaan kerja maupun kontaminasi terhadap makanan yang akan diolah oleh penjamah makanan.

Proses pembuatan minuman susu di lakukan di akhir setelah makanan siap untuk disajikan, proses pembuatan minuman susu dilakukan oleh penjamah makanan di ruang penyajian makanan dengan menggunakan takaran/gelas ukur sesuai dengan takaran yang telah tertera di ruang penyajian yang selanjutnya dimasukkan ke dalam plastik dan diikat.

d. Cara penyimpanan makanan

Hasil observasi menunjukkan bahwa tidak penyimpanan makanan. Makanan yang telah selesai diolah segera di pindahkan ke ruang penyajian untuk di tata di plate dan segera di distribusikan ke ruang pasien.

e. Kondisi pengangkutan makanan

Hasil observasi menunjukkan bahwa cara pengangkutan makanan di Instalasi Gizi RSJD dr. Arif Zainudin Surakarta sudah memenuhi syarat dengan prosentase $75 \%$. Sedangkan yang tidak memenuhi syarat dengan prosentase $25 \%$.

1. Makanan yang akan disajikan didistribusikan dengan menggunakan kereta dorong khusus untuk makanan jadi dengan kondisi tertutup dan bersih. Makanan disajikan pada plate dan tempat makan yang tertutup dan bersekat untuk setiap jenis makanan, jumlah makanan 
yang ada di dalam kereta dorong sesuai dengan jumlah pasien. Jalur distribusi penyajian makanan belum menggunakan jalur khusus, masih satu jalur dengan jalur pengangkutan troli kotor.

2. Makanan diangkut menggunakan kereta dorong pada jam-jam tertentu. Sehingga tidak bersamaan dengan jam pengangkut sampah maupun linen kotor, ini dimakhsudkan agar tidak terjadi kontaminasi antara makanan dan sampah maupun linen kotor karena belum ada jalur khusus jadi masih menggunakan 1 selasar untuk bersama.

3. Tenaga pengangkut makanan adalah petugas dari pramusaji yang telah selesai menyiapkan makanan. Saat penyajian makanan petugas menggunakan apd lengkap, seperti masker, sarung tangan, clemek, sepatu boot, dan penutup rambut.

f. Cara penyajian makanan

Berdasarkan hasil observasi terhadap cara penyajian makanan atau distribusi makanan sudah dalam katagori memenuhi syarat yaitu dengan presentase $71,4 \%$. Sedangkan presentase yang tidak memenuhi syarat yaitu 28.6\%. Hasil observasi mengenai personal hygiene pramusaji masih kurang. Penyajian makanan dilakukan oleh pramusaji dengan cara mengantarkan makanan ke ruang-ruang pasien dengan jumlah sesuai dengan pasien yang berada diruang tersebut sesuai dengan menu pada hari itu

\section{Hasil pengamatan terhadap personal hygiene penjamah makanan di Instalasi Gizi RSJD dr. Arif Zainudin Surakarta.}

Dalam proses pengumpulan data, wawancara dilakukan untuk mengetahui tingkat pengetahuan penjamah makanan dalam hal sanitasi pengolahan makanan dengan memberikan beberapa pertanyaan yang berkaitan dengan sanitasi antara lain kebersihan dapur, pembuangan sampah dapur, kegunaan gudang bahan makanan, perilaku merokok, mencuci tangan sebelum menjamah makanan, pentingnya menggunakan clemek, pakaian kerja dan penutup rambut.

Hasil dari wawancara tersebut menunjukkan hasil sudah memenuhi syarat dengan prosentase $100 \%$ dari 10 orang responden yang ditanyai telah mengerti tentang pentingnya membersihkan dapur sebelum dan setelah digunakan, pentingnya membuang sampah setiap hari, pengetahuan tentang kegunaan gudang penyimpanan bahan makanan, perlunya memakai pakaian kerja, clemek, dan penutup rambut, serta para penjamah makanan telah mengetahui bahwa tidak boleh merokok saat bekerja di dapur, penjamah juga mengetahui sebelum menjamah makanan harus cuci tangan dan setelah dari kamar mandi harus cuci tangan.

Namun, pada saat peneliti melakukan observasi mengenai personal hygiene penjamah makanan menggunakan instrumen checklist disapatkan hasil observasi menunjukkan bahwa personal hygiene penjamah makanan sudah memenuhi syarat yaitu dengan prosentase $75 \%$, dan penilaian yang tidak memenuhi syarat dengan prosentase $25 \%$ karena masih terlihat penjamah makanan saat mengolah makanan tidak menggunakan sarung tangan dan masker.

\section{Hasil pengamatan terhadap kondisi Fisik Instalasi Gizi Instalasi Gizi}

RSJD dr. Arif Zainudin Surakarta terbagi atas beberapa ruangan mulai dari ruang ruang penerimaan bahan makanan, penyimpanan bahan makanan basah, penyimpanan bahan makanan kering, ruang loker karyawan, kamar mandi karyawan, ruang pengolahan, ruang pencucian dan penyimpanan peralatan masak, ruang pemantauan, ruang penyajian, ruang pencucian piring, ruang staff gizi, dan ruang kepala instalasi gizi.

Kondisi Fisik Instalasi Gizi berdasarkan hasil observasi meliputi, lantai lantai bersih tidak licin berbentuk konus, dinding berwarna terang dan mudah di bersihkan, langit-langit berwarna terang dan mudah dibersihkan, ventilasi $10 \%$ dari luas lantai, pencahayaan > 200 lux. Pada saat observasi dengan menggunakan checklist di Instalasi Gizi RSJD dr. Arif Zainudin Surakarta di dapatkan hasil sudah memenuhi syarat dengan presentase $70 \%$. Sedangkan presentase $30 \%$ tidak memenuhi syarat.

Observasi mengenai peralatan yang digunakan dari pengadaan bahan makanan sampai dengan penyajian makanan sudah dalam katagori baik, yaitu dengan menggunakan bahan yang utuh, tidak retak, tahan karat, mudah mengering, mudah dibersihkan, sehingga perlu dipertahankan atau ditingkatkan lagi.

Semua jenis limbah cair yang dihasilkan oleh Instalasi Gizi semua di proses di IPAL Rumah sakit. Namun sebelum masuk ke dalam IPAL, limbah cair yang berasal dari tempat cuci piring dan cucu peralatan air dialirkan ke bak penampungan Grease trap terlebih dahulu karena agar minyak dapat memisah dengan air, sehingga minyak tidak menggumpal dan membeku di dalam pipa dan menjadikan pipa tersumbat. Setelah minyak dan air terpisah, air akan mengalir ke bak control secara grafitasi dan selanjutnya akan mengalir ke IPAL dengan sistem pompa, gumpalan minyak atau lemak dibersihkan oleh cleaning service setiap hari.

\section{Hasil pemeriksaan kualitas Mikrobiologi} makanan

\begin{tabular}{|c|c|c|c|c|c|c|}
\hline \multirow{4}{*}{ No } & \multirow{4}{*}{$\begin{array}{c}\text { Kode } \\
\text { Sampel }\end{array}$} & \multicolumn{3}{|c|}{ Hasil Pengukuran } & \multirow{4}{*}{$\begin{array}{l}\text { Stan- } \\
\text { dar }\end{array}$} & \multirow{4}{*}{$\begin{array}{c}\text { Keterang- } \\
\text { an }\end{array}$} \\
\hline & & 1 & 2 & 3 & & \\
\hline & & Pukul & Pukul & Pukul & & \\
\hline & & 10.25 & 08.10 & 14.05 & & \\
\hline 1. & Air teh & 3 & & & \multirow{3}{*}{$\begin{array}{c}0 / 100 \\
\text { ml } \\
\text { sampel }\end{array}$} & TMS \\
\hline 2. & Air teh & \multicolumn{3}{|c|}{0} & & MS \\
\hline 3. & Air teh & & & 0 & & MS \\
\hline
\end{tabular}


Pemeriksaan sampel minuman teh siap saji dilakukan untuk mengetahui kualitas makanan dan minum,an yang disajikan oleh instalasi Gizi RSJD dr. Arif Zainudin Surakarta. Smapel untuk pemeriksaan mikrobiologi uang diambil adalah air teh. Sampel yang diambil diperiksa di Lab Instalasi Sanitasi RSJD dr. Arif Zainudin.

\section{IV.KESIMPULAN}

Berdasarkan hasil yang telah diperoleh dari observasi dan wawancara dapat disimpulkan bahwa Hygiene Sanitasi Pengolahan Makanan di Instalasi Gizi RSJD dr. Arif Zainudin Surakarta sudah baik, yang didasarkan oleh Enam Prinsip Hygiene Sanitasi Pengolahan Makanan dan Kondisi Fisik Instalasi Gizi, antara lain :

a. Kondisi enam prisip hygiene sanitasi pengolahan makanan :

1. Kondisi Pengamanan Bahan Makanan di Instalasi Gizi RSJD dr. Arif Zainudin Surakarta sudah memenuhi syarat dengan prosentase $90 \%$.

2. Kondisi Penyimpanan Bahan Makanan di Instalasi Gizi RSJD dr. Arif Zainudin Surakarta sudah memenuhi syarat dengan prosentase $75 \%$.

3. Cara Pengolahan Bahan Makanan di Instalasi Gizi RSJD dr. Arif Zainudin Surakarta sudah memenuhi syarat dengan prosentase $100 \%$.

b. Cara Penyimpanan Makanan di Instalasi Gizi RSJD dr. Arif Zainudin Surakarta sudah memenuhi syarat dengan prosentase $100 \%$.

c. Kondisi Pengangkutan Makanan di Instalasi Gizi RSJD dr. Arif Zainudin Surakarta sudah memenuhi syarat dengan prosentase 71,4\%.

d. Cara Penyajian Makanan di Instalasi Gizi RSJD dr. Arif Zainudin Surakarta sudah memenuhi syarat dengan prosentase $75 \%$.

Personal hygiene penjamah makanan di Instalasi Gizi RSJD dr. Arif Zainudin Surakarta sudah memenuhi syarat dengan prosentase $75 \%$.

Kondisi Fisik Instalasi Gizi di Instalasi Gizi RSJD dr. Arif Zainudin Surakarta sudah memenuhi syarat dengan prosentase $70 \%$.

Kualitas Mikrobiologis minuman yang dilakukan di Lab Instalasi Sanitasi RSJD dr. Arif Zainudin Surakarta dan telah dilakukan pemeriksaan sebanyak tiga kali di dapatkan hasil sudah memenuhi syarat dengan hasil pemeriksaan laboratorium dengan sampel minuman teh didapatkan hasil 0/100ml sampel.

\section{DAFTAR PUSTAKA}

Azwar, Azrul, 1985, Pengantar Sanitasi Makanan,Cetakan Keempat, Jakarta : Mutiara Sumber Widya

Depkes RI, 2004, Pengertian Hygiene Sanitasi Makanan

Depkes RI, 2006, Pengertian Penjamah Makanan

FAO, 2001, Pengertian Penjamah Makanan

FAO, 2001, Pengertian Sanitasi Makanan

https://id.wikipedia.org/wiki/Rumah_Sakit_jiwa

Kepmenkes RI No.1098/MENKES/SK/2003, tentang Persyaratan Hygienen Sanitasi Rumah Makan dan Restoran

_ No.715/MENKES/SK/V/2003, tentang Persyaratan Hygiene Sanitasi Jasa Boga. Jakarta : Depkes RI

Lukman Saksono,1986.Pengantar Sanitasi Makanan, Bandung : Penerbit Alumni

Menkes RI No. 135/Men.Kes/SK/IV/78, tentang Susunan Organisasi dan Tata Kerja Rumah Sakit Jiwa

Permenkes RI, Ditjen PPM \& PLP, 1999,Keputusan Kesehatan Lingkungan Rumah Sakit, Jakarta : DepKes RI

Permenkes RI No. 1204/Menkes/SK/X/2004, tentang Persyaratan Kesehatan Lingkungan di Rumah Sakit

, No.712/MENKES/PER/IX/1986, tentang Persyaratan Kesehatan Jasa Boga. Jakarta : Depkes RI

Sabarguna,B.S.dkk,2011, Sanitasi Makanan dan Minuman Menuju Peningkatan Mutu Efisiensi Rumah Sakit, Jakarta : Salemba Medika

Tri Cahyono,2014,Pedoman Penulisan Proposal Penelitian dan Karya Tulis Ilmiah (Edisi Revisi Ketiga), Poltekkes Kemenkes Semarang Jurusan Kesehatan Lingkungan Purwokerto

www.rsjd-surakarta.jatengprov.go.id 